Supplement of Hydrol. Earth Syst. Sci., 20, 1703-1717, 2016

http://www.hydrol-earth-syst-sci.net/20/1703/2016/

doi:10.5194/hess-20-1703-2016-supplement

(C) Author(s) 2016. CC Attribution 3.0 License.

(c) (1)

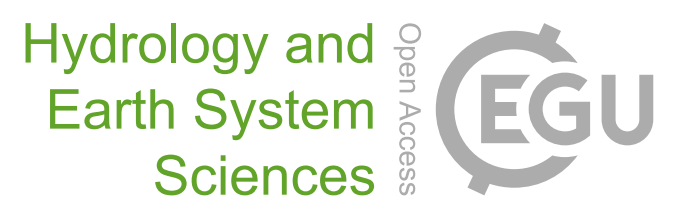

Supplement of

\title{
An ice core derived 1013-year catchment-scale annual rainfall reconstruction in subtropical eastern Australia
}

\section{Carly R. Tozer et al.}

Correspondence to: Carly R. Tozer (carly.tozer@utas.edu.au)

The copyright of individual parts of the supplement might differ from the CC-BY 3.0 licence. 
Contents of this file: Table S1-S3

\section{S1 Introduction}

This file contains supplementary information for the above article.

Table S1 shows the frequency of above/below average rainfall years for each century across the reconstruction period. Table S2 shows the frequency of 'wet' and 'dry' periods (as defined using Eq. 1 in the main paper) for each century and across the reconstruction period. The results of both Table S1 and Table S2 further highlight the inter-centennial climate variability and confirm that the instrumental period (in this case 1900-1999) does not well represent the true nature of climate variability in the WR catchment. Table S3 indicates various statistics of the rainfall distribution in each century and over the full reconstruction record. 
Table S1. Indication of the frequency of below/above average periods of varying durations in each century from 1000-1999 and for the whole reconstruction record (1000-2012) expressed as the number of periods per 100 years. The number recorded in each cell represents the number of times the particular below/above average rainfall period was experienced in each century.

\begin{tabular}{|c|c|c|c|c|c|c|c|c|c|c|c|c|c|c|c|c|c|}
\hline & & \multicolumn{16}{|c|}{ No. of consecutive BELOW average years } \\
\hline & Period & 1 & 2 & 3 & 4 & 5 & 6 & 7 & 8 & 9 & 10 & 11 & 12 & 13 & 14 & 15 & 16 \\
\hline \multirow{13}{*}{ 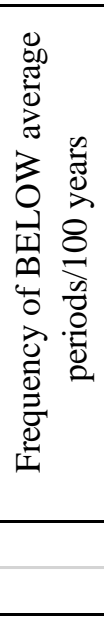 } & 1000-1099 & 8 & 5 & 5 & 4 & & & & & & & & & & & & \\
\hline & $1100-1199$ & 12 & 7 & 6 & 1 & & & & & & & & & & & & \\
\hline & 1200-1299 & 10 & 11 & 3 & 1 & & 1 & & & & & & & & & & \\
\hline & 1300-1399 & 17 & 3 & 2 & & & & & & & & & & & & & \\
\hline & 1400-1499 & 13 & 5 & 1 & & & & & & & & & & & & & \\
\hline & $1500-1599$ & 8 & 2 & 4 & & & & & & & & & & & & & \\
\hline & 1600-1699 & 12 & 4 & & 1 & 1 & & & & & & & & & & & \\
\hline & 1700-1799 & 15 & 3 & 4 & & & 1 & & & & & & & & & & \\
\hline & 1800-1899 & 14 & 2 & & 1 & & & & & & & & & & & & \\
\hline & 1900-1999 & 9 & 8 & 2 & 2 & & & 1 & & & & & & & & & \\
\hline & $1000-2012$ & 11.8 & 4.9 & 2.9 & 1.0 & 0.1 & 0.2 & 0.1 & & & & & & & & & \\
\hline & & \multicolumn{16}{|c|}{ No. of consecutive ABOVE average years } \\
\hline & Period & 1 & 2 & 3 & 4 & 5 & 6 & 7 & 8 & 9 & 10 & 11 & 12 & 13 & 14 & 15 & 16 \\
\hline \multirow{11}{*}{ 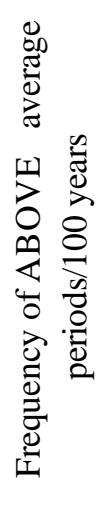 } & 1000-1099 & 7 & 4 & 9 & & & & 1 & & & & & & & & & \\
\hline & \begin{tabular}{|l|l|}
$1100-1199$ \\
\end{tabular} & 11 & 6 & 5 & 4 & & & & & & & & & & & & \\
\hline & $1200-1299$ & 17 & 5 & 3 & & & 1 & 1 & & & & & & & & & \\
\hline & \begin{tabular}{|l}
$1300-1399$ \\
\end{tabular} & 9 & 3 & 3 & 2 & 1 & 1 & 1 & & & 2 & & & & & & \\
\hline & 1400-1499 & 5 & 3 & 3 & 2 & 1 & 2 & & 1 & & 1 & & 1 & & & & \\
\hline & \begin{tabular}{|l|l|}
$1500-1599$ \\
\end{tabular} & 2 & 3 & 1 & & & 3 & & 1 & 2 & & 1 & & & & & \\
\hline & \begin{tabular}{|l}
$1600-1699$ \\
\end{tabular} & 3 & 5 & & 3 & 2 & 3 & 1 & & & & & & & & & 1 \\
\hline & 1700-1799 & 8 & 6 & 2 & 5 & & 2 & 1 & & & & & & & & & \\
\hline & 1800-1899 & 2 & 5 & 2 & 1 & 1 & 1 & & 1 & & 1 & 1 & & & & & 1 \\
\hline & 1900-1999 & 9 & 8 & & 3 & 2 & & 1 & & & & & & & & & \\
\hline & $1000-2012$ & 7.4 & 4.7 & 2.8 & 2.1 & 0.7 & 1.3 & 0.6 & 0.3 & 0.2 & 0.4 & 0.2 & 0.1 & & & & 0.2 \\
\hline
\end{tabular}


Table S2. Frequency of 'wet' and 'dry' periods of varying durations in each century from 10001999 and for the whole reconstruction record (1000-2012) expressed as the number of periods per 100 years. The number recorded in each cell represents the number of times the particular below/above average rainfall period was experienced in each century. 'Wet' and 'dry' are defined using $x=0.3$ in Eq. 1 in the main paper.

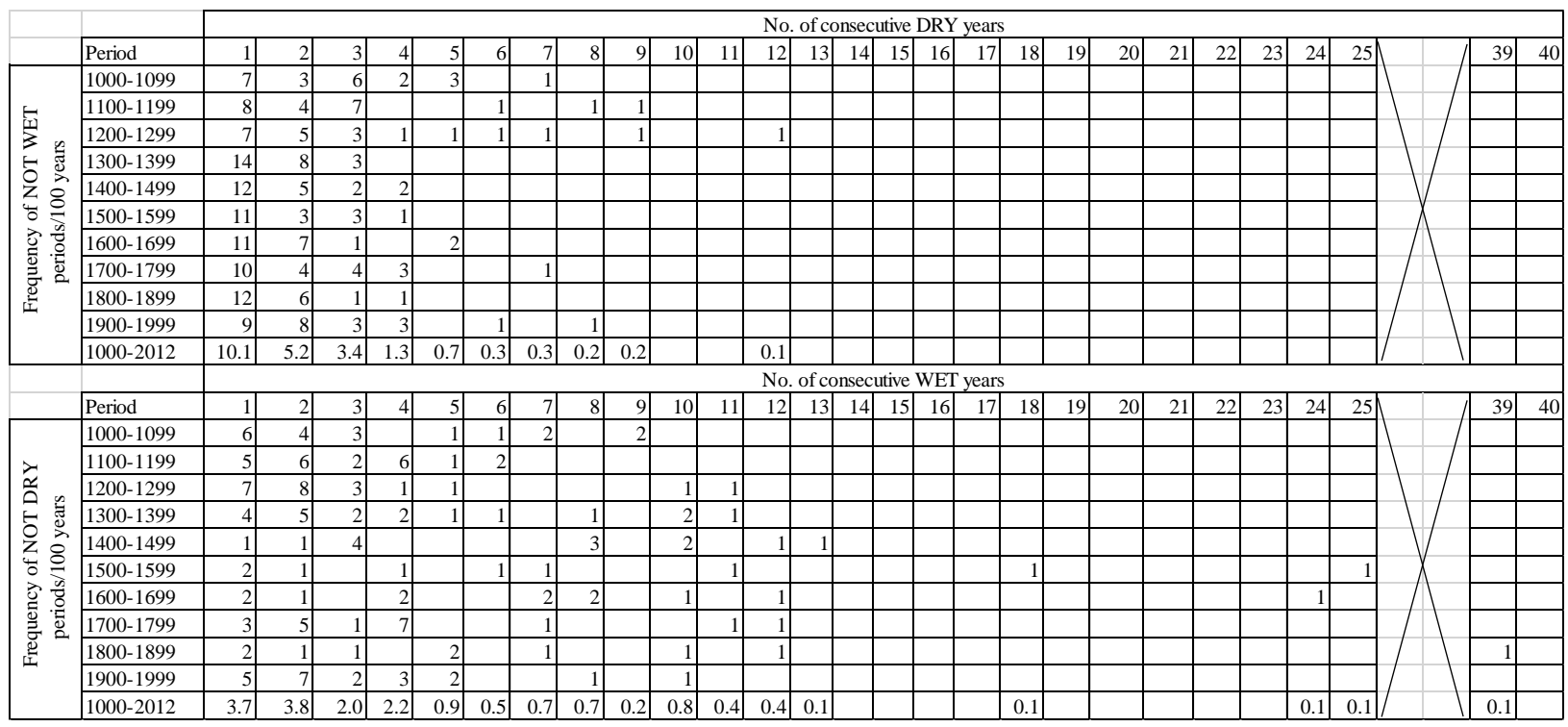


Table S3. For each century from 1000-1999 and the full reconstruction, the mean rainfall, the mean rainfall as a ratio of the instrumental mean $(1100.0 \mathrm{~mm})$, the percent of below/average years, and the number of 'wet' and 'dry' years. 'Wet' and 'dry' are defined using $x=0.3$ in Eq. 1 in the main paper (see also Table 2 in the main paper).

\begin{tabular}{|c|c|c|c|c|c|c|}
\hline Period & $\begin{array}{c}\text { Mean } \\
(\mathrm{mm})\end{array}$ & $\begin{array}{c}\text { Mean relative to } \\
\text { instrumental mean }\end{array}$ & $\begin{array}{c}\text { \% below } \\
\text { average }\end{array}$ & $\begin{array}{c}\text { \% above } \\
\text { average }\end{array}$ & $\begin{array}{c}\text { \% DRY } \\
\text { years }\end{array}$ & $\begin{array}{c}\% \text { WET } \\
\text { years }\end{array}$ \\
\hline $1000-1099$ & 1107.6 & 1.01 & 49 & 51 & 61 & 68 \\
\hline $1100-1199$ & 1086.5 & 0.99 & 48 & 52 & 67 & 63 \\
\hline $1200-1299$ & 1098.1 & 1.00 & 51 & 49 & 62 & 62 \\
\hline $1300-1399$ & 1135.0 & 1.03 & 30 & 70 & 40 & 77 \\
\hline $1400-1499$ & 1153.5 & 1.05 & 25 & 75 & 35 & 84 \\
\hline $1500-1599$ & 1161.0 & 1.06 & 24 & 76 & 31 & 85 \\
\hline $1600-1699$ & 1140.5 & 1.04 & 29 & 71 & 37 & 83 \\
\hline $1700-1799$ & 1122.5 & 1.02 & 40 & 60 & 50 & 69 \\
\hline $1800-1899$ & 1156.4 & 1.05 & 21 & 79 & 30 & 86 \\
\hline $1900-1999$ & 1103.1 & 1.00 & 47 & 53 & 61 & 66 \\
\hline $1000-2012$ & 1126.1 & 1.02 & 37 & 63 & 48 & 74 \\
\hline
\end{tabular}

